\title{
LAMENTO DE UM BLUE
}

\section{Olga de Sá⿱}

RESUMO: O texto focaliza, principalmente, a edição especial comemorativa da publicação dos 40 anos de $A$ hora da estrela e da morte de sua Autora, Clarice Lispector.

PALAVRAS-CHAVE: A hora da estrela; Clarice Lispector; Mulher; Pobreza.

Apropriei-me de um dos vários títulos de $A$ bora da estrela propostos pela própria Clarice Lispector, para denominar este meu modesto ensaio, na esperança que isso o torne mais simpático aos leitores.

Estamos comemorando os 40 anos de publicação de $A$ hora da estrela e da morte de sua autora, Clarice Lispector.

A Editora Rocco publicou uma edição especial da obra, com manuscritos originais de Clarice e escolheu ensaios de estudiosos brasileiros e estrangeiros para nela figurar: $\mathrm{Pa}$ loma Vidal que se debruçou sobre os manuscritos, Hélène Cixous, Colm Tóibín, Florencia Garramuño, Nádia Batella Gottlib, Clarisse Fukelman e Eduardo Portella, que focalizaram diferentes aspectos deste livro publicado por Clarice dois meses antes de sua morte.

\footnotetext{
* Doutora em Comunicação e Semiótica, Mestre em Teoria Literária pela PUC-SP. Membro do Grupo de pesquisa do Programa de Pós-graduação em Literatura e Crítica Literária da PUC-SP. Assessora de direção do Centro Universitário Teresa D'Ávila - UNIFATEA - Lorena. Autora dos livros A escritura de Clarice Lispector (1979) pela Vozes e Clarice Lispector: a travessia do oposto (1993), pela Annablume.
} 
Todos esses ensaios foram publicados antes de virem à luz os manuscritos, ou como prefácio, posfácio, apresentação de $A$ hora da estrela, salvo os de Hélène Cixous e Nádia Gotlib, que apareceram em Revistas.

Não foi o que aconteceu com os ensaios acima, mas depois da publicação dos manuscritos, o leitor ou o crítico da obra clariceana, terá que refazer seus passos, no mínimo por cautela, e no embalo desse vai-e-vem da escritura de Clarice, que escreve à medida que reescreve a morte de Macabéa, antes de dar-lhe forma definitiva:

Acho com alegria que ainda não chegou a hora de estrela de cinema de Macabéa morrer. Pelo menos ainda não consigo adivinhar se lhe acontece o homem louro e estrangeiro. Rezem por ela e que todos interrompam o que estão fazendo para soprar-lhe vida, pois ela está por enquanto solta no acaso como a porta balançando ao vento no infinito. (LISPECTOR, 1977, p. 100).

O ensaio de Hélène Cixous intitulado "Extrema fidelidade" celebra seu sonho de abordar o último texto de um grande escritor, "um texto que seria escrito com as últimas forças, com último alento” (CIXOUS in LISPECTOR, 2017, p. 131).

A hora da estrela é esse último alento de Clarice: "Escreveu-o quando ela já quase não era mais ninguém sobre a terra. Em seu lugar imenso, abria-se a grande noite". (CIXOUS in LISPECTOR, 2017, p. 132). É um pequeno livro, quase um caderno, mas é um dos maiores livros do mundo, observa Cixous.

Este livro foi escrito com uma mão cansada e apaixonada. Clarice já tinha, de certa maneira, deixado de ser uma autora, de ser uma escritora.

É o último texto, aquele que vem depois. Depois de todo livro. Depois do tempo. Depois do eu. Pertence à eternidade, a esse tempo de antes de depois do eu que nada pode interromper. A esse tempo, a essa vida secreta e infinita de que somos fragmentos. (CIXOUS in LISPECTOR, 2017, p. 132 - Grifo da autora).

Hélène Cixous diz que esse livro não fala sequer seu nome, hesita entre 13 títulos para escolher um: 
A culpa é minha ou $A$ hora da estrela ou Ela que se arranje ou $O$ direito ao grito ou . Quanto ao futuro. ou Lamento de um blue ou Ela não sabe gritar ou Uma sensação de perda ou Assovio no vento escuro ou Eu não posso fazer nada ou Registro dos fatos antecedentes ou História lacrimogênica de cordel ou Saida discreta pela porta dos fundos (LISPECTOR, 2017, p. 5)

Cixous desenvolve o que ela chama "uma modesta meditação sobre esse livro" (p. 133), incluindo Macabéa, “essa quase mulher, é uma mulher quase não mulher, mas é de tal modo quase-não-mulher que talvez seja mais mulher que toda mulher" (CIXOUS in LISPECTOR, 2017, p. 134).

Para ler o ensaio de Hélène Cixous, o leitor tem de despojar-se de seu eu, como Clarice, a narradora de $A$ bora da estrela. O narrador, Rodrigo S. M., é o "alter ego" de Clarice, mas ambos se transfiguram e o leitor tem de despojar-se de seu eu, como fazem os narradores.

"A ação desta história terá como resultado minha transfiguração em outrem e minha materialização enfim em objeto" (LISPECTOR, 1977, p. 26). E, em outro lugar, diz o narrador, aliás, Clarice Lispector:

Esse eu que é vós pois não aguento ser apenas mim, preciso dos outros para me manter de pé, tão tonto que sou, eu enviesado, enfim que é que se há de fazer senão meditar para cair naquele vazio pleno que só se atinge com a meditação (LISPECTOR, 1977, p. 7).

Clarice ia frequentemente com Olga Borelli a um mercado no Rio de Janeiro, a feira de São Cristóvão; na feira reuniam-se os migrantes nordestinos pobres, e o futuro namorado de Macabéa apareceu, para Clarice, lá, um dia.

Segundo Olga Borelli, Clarice comeu beiju e rapadura, sentou-se num banco e escreveu umas quatro ou cinco páginas sobre Olímpico. Macabéa também nasceu assim (Cf. MOSER, 2009, p. 542): “É que numa rua do Rio de Janeiro peguei no ar de relance o sentimento de perdição no rosto de uma moça nordestina” (LISPECTOR, 2017, p. 48).

Por sugestão de Marina Colasanti e Affonso Romano de Sant 'Anna, Clarice, em seus últimos anos, vinha frequentando uma cartomante no bairro do Méier. Essa mulher, chamada D. Nadir, geralmente dava a Clarice vaticínios felizes. O mesmo fez a cartomante 
Madame Carlota com Macabéa. As previsões de Madame Carlota acontecem: a moça, de fato, "encontra" o estrangeiro loiro, numa Mercedes. Mas de modo negro e irônico, encontra a morte. (MOSER, 2009, p. 551)

Em outubro, alguns dias depois da publicação de $A$ bora da estrela, Clarice Lispector foi subitamente hospitalizada. No táxi, a caminho do hospital, ela disse: "Faz de conta que a gente não está indo para o hospital, que eu não estou doente e que nós estamos indo para Paris", lembrava-se Olga Borelli.

Começaram a fazer planos e a falar de passeios em Paris. O motorista do táxi, coitado, já cansado de trabalhar por toda uma noite, perguntou tímido: "Eu também posso ir nesta viagem”? E Clarice falou: "Lógico que pode, e ainda pode levar a namorada" E ele: “Minha namorada é uma velhinha de setenta anos, e não tenho dinheiro. Clarice respondeu: "Ela vai também, faz de conta que você ganhou na loteria esportiva". Na hora de descer, em frente ao hospital, conta Olga, Clarice perguntou o preço da corrida. Apenas vinte cruzeiros, e ela deu duzentos" (MOSER, 2009, p. 553).

Clarice tinha um câncer terminal, mas não lhe deram tal informação. Ela tinha dito que "cada um escolhe o modo de morrer" e não dava sinais de que sabia o que estava acontecendo. Moser é de opinião que ela sabia, mas vestia uma máscara de coragem, para não afligir os que a acompanhavam. Disse que queria morrer escrevendo. Em seu leito de morte ela retornou ao mito que criara em torno de seu nome, lis no peito (MOSER, 2009, p. 554).

Sou um objeto querido por Deus. E isso me faz nascerem flores no peito. Ele me criou igual ao que escrevi agora: sou um objeto querido por Deus e ele gostou de me ter criado como eu gostei de ter criado a frase. E quanto mais espírito tiver o objeto humano mais Deus se satisfaz. (BORELLI, 1981. p. 61).

Lírios brancos encostados à nudez do peito. Fortemente sedada, ela ainda ditava palavras a Olga, na manhã de 9 de dezembro.

Às dez e meia da manhã de 9 de dezembro de 1977, ela morreria segurando a mão de Olga. 
Clarice não pode ser enterrada no dia 10, o dia de seu aniversário, de 57 anos, porque caiu no Shabat, e ela era de família judaica. No dia 11, no cemitério do Caju, Clarice foi sepultada de acordo com o ritual ortodoxo. Seu corpo foi envolvido num lençol de linho branco, posicionaram sua cabeça num travesseiro cheio de terra e a colocaram num caixão simples de madeira.

Foram lidos o Salmo 91, a oração fúnebre "El malei rahamim” e o Kadish dos enterros; três pazadas de terra foram lançadas sobre o caixão enquanto soavam as palavras do Gênesis: "Da terra vieste e à terra voltarás".

Na lápide, gravado em hebraico, o nome oculto: “Chaya bat Pinklas. Chaya, filha de Pinklas" (MOSER, 2009, p. 557).

Sobre o túmulo leem-se as palavras de Clarice: "Dar a mão a alguém foi sempre o que esperei da alegria”.

Nádia Batella Gotlib termina sua biografia Clarice uma vida que se conta, de 1995, citando fragmentos da escritora:

Dentro do mais interior de minha casa morro neste fim de ano exausta. Eu, eu, se não me falha a memória, morrerei. No que precede o acontecimento, é lá que eu vivo. Espero viver sempre às vésperas. E não no dia. O clímax de minha vida será a morte. (GOTLIB, 1995, p. 482).

Portanto, na comemoração dos 40 anos de A hora da estrela e da morte de Clarice, ninguém espere requintes, brilho de estrelas. Aliás, avisa o narrador Rodrigo S. M.: "Nada cintilará, trata-se de matéria opaca e por sua própria natureza desprezível por todos”. (LISPECTOR, 1977, p. 21)

A estrela protagonista é "estrela de cinema" e só aparece mesmo na hora da morte. Essa é a hora da estrela.

Sempre houve quem achasse a escritura de Clarice alienada, afastada do fato social e que ela se redimiu dessa alienação quando escreveu $A$ hora da estrela. A protagonista nordestina, Macabéa, ao existir, denunciou todo o contexto social brasileiro e, por extensão, a injustiça do mundo. 
A hora da estrela é também um "canto paralelo". A quê? A todos os grupos dominantes.

Vivendo na grande cidade do Rio de Janeiro, num quarto alugado, com quatro balconistas das Lojas Americanas, não longe do cais do porto, lugar de marinheiros e prostitutas, Macabéa pertence, socialmente falando, à classe dos marginalizados. E denuncia: a marginalização da mulher, de muitas espécies de mulheres: as feias, as incompetentes, mal cheirosas, órfãs de pai e de mãe, encardidas, raquíticas, tuberculosas, aidéticas, mal amadas, sonhadoras, esfomeadas, balconistas, solteironas, prostitutas, manchadas de "panos", as velhas, donas de casa, neuróticas.

Denuncia a marginalização do homem: os médicos de pobres, os valentões, os machistas, os exploradores, os pequenos ladrões, os gringos loiros em automóveis assassinos, os maridos chatos, os hipocondríacos.

Denuncia a marginalização da sociedade, do sistema: patrocínio da Coca-Cola à literatura e aos terremotos, Rádio Relógio produzindo hora e cultura de massa, fitas em tecnicolor em cinema pulguento, bairros de mulher-dama e marinheiros, pensões alugando vagas para moças, sociedade de anúncios, de fetos jogados embrulhados na lata de lixo. (Cf. SÁ, 1979, p. 224).

"Macabéa é vida primária, puramente orgânica, que respira, respira, respira” (LISPECTOR, 1977, p. 17).

Tem seus atos sublimes como comprar uma rosa, extasiar-se com a beleza do arcoíris, admirar fogos de artifício, sonhar com o futuro indo à cartomante, perceber o transitório do tempo que escorre na marcação da Rádio Relógio, esperar o galo cantar, ouvir o som das palavras como se fossem coisa-substância da poesia e ser atropelada sob o signo do centauro, enquanto um cavalo empina ao longe, "em gargalhada de relincho". (LISPECTOR, 1977, p. 95)

Mas voltemos à vida de Clarice. Informa-nos Benjamin Moser: em meados de 1962, Clarice conheceu a poetisa norte-americana Elizabeth Bishop, que morava no Brasil desde 1951. Bishop conheceu Clarice e gostou dela, de seu nome e de seus contos. Começou a 
traduzir alguns contos de Clarice, mas as esperanças dela numa colaboração literária se frustraram, quando Clarice, inexplicavelmente, sumiu. (Cf. MOSER, 2009, p. 372).

Bishop escreveu a Lowell que tinha traduzido cinco contos de Clarice e a New Yorker estava interessada em publicá-los. Clarice precisava de dinheiro e o dólar estava alto.

\begin{abstract}
Mas no momento - justamente quando eu ia despachar pelo correio todos os contos, menos um - ela sumiu - completamente - não me procura há seis semanas! [...] - não está zangada nem nada - e parece ter adorado as traduções, as cartas das pessoas interessadas etc.. Estou perplexa; [...] É o "temperamento" dela, talvez ou talvez, mais provavelmente, apenas aquela "inércia esmagadora" que a gente encontra por toda parte - [...] (MOSER, 2009, p. 372).
\end{abstract}

Mas, segundo o mesmo Moser, o desaparecimento de Clarice talvez tivesse a ver com uma crise pessoal. Em 1962, o primeiro amor de Clarice, Lúcio Cardoso, depois de uma vida inteira de abuso de álcool e remédios, depois de um espasmo, em maio, apesar de avisado pelo médico, continuou a beber e a tomar bolinhas; "deu certo", como ele disse à irmã Maria Helena, e ele morreu. Clarice sofreu muito essa perda.

Quando tem notícias de Clarice, Bishop achou que ela estivera doente. As tentativas da poetisa americana, ainda que relutantes, de promover Clarice em inglês, acabaram sendo recompensadas. Foram publicados três contos em tradução de Bishop e, em 1967, a primeira tradução de um romance $A$ maçã no escuro. $O$ tradutor não foi Bishop, que achava a tradução de uma obra daquela extensão “uma chatice \& perda de tempo”. E sim Gregory Rabassa, o decano dos tradutores de ficção latino-americana.

Ele conhecera Clarice alguns meses depois do derrame de Lúcio, quando ela foi convidada para ir aos Estados Unidos, a um Congresso literário, no Texas. Clarice leu para Bishop o texto de sua palestra. Diz Bishop: "Mas ela é incorrigível, realmente".

Foi a primeira visita de Clarice aos Estados Unidos desde que deixara Washington, em 1959, e seria a última. Durante seus poucos dias em Austin ela causou uma impressão estupenda. Gregory Rabassa disse que "ficou atônito ao conhecer aquela pessoa rara, que se parecia com Marlene Dietrich e escrevia como Virginia Woolf”. Um repórter de jornal escreveu: 'A senhora Lispector é uma ruiva estonteante dotada do carisma de uma estrela 
de cinema, capaz de iluminar todo e qualquer aposento no qual ela entre'. (MOSER, 2009, p. 376).

O cônsul brasileiro julgou-se no dever de convidá-la para jantar. Ela conta que ele a levou a um restaurante de terceira classe, daqueles com toalhas quadriculadas de vermelho e preto. Pediu peixe para a senhora (peixe é barato), um bife bem sangrento para ele (a carne é cara). Clarice nem pediu sobremesa, para economizar.

Sua conferência foi uma exposição muito convincente sobre literatura, assevera Rabassa.

O tema foi literatura de vanguarda. Afirma que toda arte verdadeira é de vanguarda, uma vez que toda verdadeira vida é experimentação e toda obra que não o é não passa de imitação. Ela acrescentou um apêndice desesperador:

Quanto ao fato de eu escrever, digo - se interessa a alguém - que estou desiludida. É que escrever não me trouxe o que eu queria, isto é, paz. Minha literatura, não sendo de forma alguma uma catarse que me faria bem, não me serve como meio de libertação. Talvez de agora em diante eu não mais escreva, e apenas aprofunde em mim a vida. Ou talvez esse aprofundamento da vida me leve de novo a escrever. De nada sei. (in: MOSER, 2009, p. 376-377).

E foi o que aconteceu. Para ela, parar de escrever era morrer.

Talvez, como observa Moser, a imagem mais duradoura de Clarice, no final da vida, vem de uma entrevista que ela deu ao jornalista Júlio Lerner, em fevereiro de 1977. Ela chegou com Olga Borelli aos estúdios da TV Cultura em São Paulo para participar de um programa sobre cinema. O diretor da emissora aproveitou a ocasião para pedir-lhe uma entrevista só com ela, pedido que ela, para espanto geral, aceitou. Lerner foi chamado em sua sala, conseguiu um estúdio em cinco minutos, às 4:45h da tarde; tinha apenas meia hora para a entrevista devendo liberar o estúdio quinze minutos antes disso. Lerner fez as perguntas que lhe foram ocorrendo.

Declarou que lhe era mais fácil comunicar-se com crianças que com adultos; que a criança é solta, tem fantasia e o adulto é triste e solitário. Mas ela mesma não se sentia 
solitária, tinha muitos amigos, era alegre e só estava triste naquele dia, porque estava cansada.

Perguntada se se considerava uma escritora popular, respondeu que não, porque a consideravam uma escritora hermética. Mas ela não era hermética para si mesma e só havia um conto que ela não compreendia muito bem: "O Ovo e a galinha" (foi o conto que ela apresentou no Congresso de bruxos, em Bogotá.), aliás, que ela vê com o maior carinho por ser um mistério para ela e o "Mineirinho", um bandido que foi morto com treze balas, quando uma só bastava. Ela ficou muito revoltada.

Clarice confessa que os estudantes universitários não a procuram muito, pois parecem ter medo de não serem recebidos por ela, de atrapalhá-la. Quando a procuram, vencendo a própria timidez, ficam perfeitamente à vontade, entram na sua casa, tomam café e ela os trata como amigos. De seus trabalhos, os que ela acredita que mais atinja o público jovem, ela diz que depende.

Depende inteiramente. Por exemplo, o meu livro A paixão segundo G.H., um professor de português do Pedro II veio lá em casa e disse que leu quatro vezes o livro e não sabe do que se trata. No dia seguinte uma jovem de dezessete anos veio me visitar e disse que esse livro é o livro de cabeceira dela. Quer dizer, não dá para entender. (MOSER, 2009, p. 536).

O mesmo, diz ela, aconteceu com relação a outros de seus trabalhos. Ou toca ou não toca. Entendê-la não é questão de inteligência e sim de sentir, de entrar em contato. Ela ganha na releitura, o que é um alívio. Antes, ninguém a entendia, agora a entendem. Algo mudou, porque ela mesma não mudou, não fez concessões.

Perguntada se acontece de produzir alguma coisa e em seguida, rasgar, ela responde que sim, não por reflexão, mas por raiva de si mesma. Está cansada de si mesma. Não renasce e se renova a cada obra nova? "Bom (ela respira antes de erguer finalmente os olhos) agora eu morri. Vamos ver se eu renasço de novo. Por enquanto eu estou morta. Estou falando de meu túmulo”. (Cf. MOSER, 2009, p. 537). 
Clarice cochicha um pedido a Lerner, de que a entrevista só seja exibida depois de sua morte, no que foi atendida.

Em A hora da estrela, Macabéa esforçava-se, muda, para viver.

Seu esforço de viver parecia uma coisa, que nunca experimentara, virgem que era ao menos intuira, pois só agora entendia que mulher nasce mulher desde o primeiro vagido. O destino de uma mulher é ser mulher (LISPECTOR, 1977, p. 101).

O Autor de $A$ bora da estrela, o autor de Macabéa, o narrador que deseja transgredir os próprios limites, se cansa com o "definível” e ama os "sussurros", escreve de "ouvido", por "motivo grave de força maior", se sente culpado, e diz no início do livro: tenho de “com mãos de dedos duros enlameados apalpar o invisível na própria lama”. (SÁ, 1993, p. 226).

Suzi Frankl Sperber publicou um estudo sobre $A$ bora da estrela, intitulado "Jovem com ferrugem”, no qual capta o modo sutil de Clarice abordar a temática social, conforme podemos constatar:

Clarice Lispector apresenta a estrutura interna do ser humano massacrado. Com este processo, aparentemente de pura introspecção e de pura fabulação filosófica, questiona o mundo organizado e a cultura dominante, resgatando do preconceito os ofendidos e humilhados. (SPERBER, 1983, p. 160).

Como bem observa a mesma autora, não só os ofendidos e humilhados são resgatados, mas também as donas de casa, a pequena burguesia sem espaço definido no mundo do trabalho. Macabéa é a "diferente", a "marginal", e a ela temos acesso, revirando pelo avesso a estrela de seu destino, lido na pauta da felicidade por sua companheira de desdita - a cartomante. Estrela mortuária, que dela fez a estrela do "écran” daquele público, à luz de uma vela acesa, a seu lado, na sarjeta. (SÁ, 1993, p. 226).

Macabéa é um grau zero na escala social, é o "neutro vivo" da coisa; semi-analfabeta, grotesca, até certo ponto ridícula. O narrador inexiste sem a personagem. "Nestes últimos três dias sozinho sem personagens, despersonalizo-me e tiro-me de mim como 
quem tira uma roupa. Despersonalizo-me a ponto de adormecer". (LISPECTOR, 1977, p. $85)$.

Macabéa é fascinada pelo som das palavras: "efemérides/efeméricas”, "Carolus”, “álgebra”, “cultura", "eletrônico", "renda per capita", “conde," "Una furtiva lacrima”, "mimetismo", "Caruso", "Alice no país das maravilhas".

Aliás, todo o livro está pontuado de provérbios ou ditos populares, que são a memória "cantada" do povo, com a qual ele armazena sua sabedoria: Quem cai do chão não passa, lá onde judas perdeu as botas, quem espera sempre alcança, o que você pede chorando que eu não lhe de cantando, ninguém ensina cachorro a abanar o rabo, cara de quem comeu e não gostou, dessa vaca não sai leite, quem não se enfeita por si se enjeita (SÁ, 1993, p. 227).

Criando Macabéa, construindo-a como ser de linguagem, para denunciar a alienação da sociedade em que vive, o escritor procura a salvação, conquistando também seu espaço de vida. Seu direito à existência. Embora Macabéa não tenha um espaço seu, o artista também sobrevive pelas possibilidades que tem de transformar "em ouro" as dores e a fome dos outros.

Focaliza-se assim o artista contemporâneo não só defendendo e até criando o espaço da arte - seu "grito ontológico" por saber que também ele não faz a menor falta -, mas também seu sentimento de culpa, que ele procura redimir pelo cuidado, pois ama a sua personagem: Ah, se pudesse eu pegar Macabéa, dar-lhe um bom banho, um prato de sopa quente, um beijo na testa enquanto a cobria com um cobertor. E fazer que quando ela acordasse encontrasse simplesmente o luxo de viver. (LISPECTOR, 1977, p. 102).

Sá observa que a marginalização do escritor parece maior, na ótica de Clarice: porque se Macabéa (traída por ele ao ser criada; salva por ele, ao morrer), tem na hora da morte sua hora de estrela, o escritor que mata sua personagem também morre com o texto, recebe na cara a ultrajante pergunta de César assassinado: “Até tu, Brutus?"

O impasse que deflagra o artista que se vê inútil e que de uma certa maneira identifica-se com a inutilidade da sua personagem, embora ambos pertençam a diferentes cons- 
ciências de classe, faz com que o discurso bidimensional reflita a face consciente e agonizante do artista e, por outro lado, a face inconsciente da raquítica nordestina, que sorri para todos, que perambula na cidade grande, com fome, doente e feliz. (BILENKY, 1979).

Clarice desconfia da linguagem, mas sua desconfiança não é de ordem teórica. Sua ontologia da palavra, assim como sua metafísica (do ser) é empírica e vivenciada como escritura, exercício de vida, que ela alimenta de seu próprio sumo e que a realimenta continuamente. É um "partejar do espírito”, uma espécie de "maiêutica” socrática da linguagem, uma forma de conhecimento. Era uma forma de compreender a vida. Escrevendo ela compreendia. E não, compreendendo, ela escrevia. Escrever espalhava-se por dentro dela como uma espécie de erotismo. Ela disse, segundo testemunha Olga Borelli: "[...] cheguei mesmo à conclusão de que escrever é a coisa que mais desejo no mundo, mesmo mais que amor" (BORELLI, 1981, p. 114).

Por isso, o leitor de Clarice não pode ser simplesmente um ouvido que escuta ou um olho que vê, mas tem de ser a mão que segura a sua. Como foi na hora de morrer, sua hora de estrela. Enquanto Olga Borelli segurava sua mão, ela ainda escrevia. (Cf. Borelli, op. cit., p. 61-62).

Abominava a literatura como divertimento, ornamento, forma de aparecer, de projetar-se.

A 17 de dezembro de 1982, Olga Borelli transmitiu ao público que lotava o auditório da Biblioteca Municipal Mário de Andrade, em São Paulo, uma conferência de Clarice e projetou um filme de vinte minutos sobre o universo clariceano. A ambiência eram objetos pessoais da escritora, seus textos e músicas de sua predileção. O tema abordava a literatura e a vanguarda.

Declara não ter o hábito de pensar o fato literário, encarar a literatura de fora para dentro.

Recusa-se a considerar a vanguarda como experimentação. Toda verdadeira arte é experimentação, a vida é experimentação. Vanguarda é crescimento, maturação. 
Sua postura questionadora sobre escrever/viver foi porque, se ela se compreendia escrevendo, a palavra escrita, para ela, passava a ser um instrumento da existência.

O drama existencial de Clarice é, ao pé da letra, um drama fáustico.

Não por meio de filtros e estudos, fechada num gabinete gótico, entre retortas. Mas, ela também possuía seu gabinete, uma cela de monge, com a máquina de escrever e seus papeis de apontamentos, a garrafa térmica de café e a Coca-Cola. [...] Vendeu a alma para saber, vendeu a alma para escrever: 'Escrevo, logo existo', eis sua fórmula existencial, que Descartes tinha baseado no Cogito e Benedito Nunes formulou para ela, em termos de narrativa: ‘ Narro, logo existo’. (SÁ, 1993, p. 238).

Escrevia para compreender. Duvidar da palavra era duvidar da forma como lhe escorria a existência. Nasceu incumbida. Na sua escritura, na sua sinuosa marcha de pantera.

Em $A$ bora da estrela, o narrador é uma das personagens principais.

Desvenda-se na narrativa a sua problemática interior e à medida que nos faz conhecer a protagonista, também conhece a própria identidade. Aliás, toda a ficção de Clarice é da espécie metafísica do 'nosce te ipsum' socrático. Ironia e maiêutica da própria escritura. "A ação dessa história terá como resultado minha transfiguração em outrem e minha materialização em objeto." Sim, e talvez encontre a flauta doce em que eu me enovelarei em macio cipó. (LISPECTOR, 1977, p. 26). (SÁ, 1993, p. 273).

O narrador cria um destino, moldando Macabéa sobre seu próprio destino e solidão. Morre com Macabéa. Clarice sabe que o narrador inventa o mundo, segundo sua imagem e semelhança. Morreu Macabéa, morreu o narrador, morreu Clarice.

As coisas são sempre vésperas e se ela não morre agora está como nós na véspera de morrer, perdoai-me lembrar-vos porque quanto a mim não me perdoo a clarividência. (LISPECTOR, 1977, p. 101).

O escritor: Por que escreve? Porque captou o espírito da língua [...] e escreve não por causa do assunto ou da protagonista nordestina, 'mas por motivo grave de força maior' porque tem perguntas não respondidas para fazer. (SÁ, 1993, p. 275). 
Enquanto tiver perguntas e não houver respostas continuará a escrever. Essa é a dor que perpassa a narrativa, indicada pela dor de dentes que atravessa a história. A dor do narrador, a dor do escritor, a dor do leitor, a dor de Clarice, do homem, enfim, a dor da condição humana, a dor de viver e de escrever. No mundo, há falta de felicidade. Palavra doida, diz o narrador, inventada pelas nordestinas que andam por aí, aos montes. O leitor deve lembrar-se da pergunta de Joana-menina à professora contrafeita em Perto do coração selvagem: 'Ser feliz é para se conseguir o quê?’ (1990, p. 26).

O escritor sobrou no mundo, nada mais tem a fazer nele, a não ser esperar a morte.

Tem mais dinheiro que os esfomeados e se sente culpado. Não tem classe social. [...] marginalizado que sou. A classe alta me tem como um monstro esquisito, a média com desconfiança de que eu possa desequilibrá-la, a classe baixa nunca vem a mim. Não, não é fácil escrever. É duro como quebrar rochas. Mas voam faíscas e lascas como aços espelhados. (LISPECTOR, 1977, p. 24).

Faz-se pobre. Dorme pouco, adquire olheiras escuras, não faz a barba, anda nu ou em farrapos, abstém-se de sexo e de futebol, tudo para ficar ao nível de sua personagem nordestina. Escrevo por não ter nada a fazer no mundo: sobrei e não há lugar para mim na terra dos homens. Escrevo porque sou um desesperado e estou cansado, não suporto mais a rotina de me ser e se não fosse a sempre novidade que é escrever, eu me morreria, (LISPECTOR, 1977, p. 27).

Diz Nádia Gotlib que desde 1956, quando terminou $A$ maçã no escuro, Clarice não escreveu mais romance até redigir o seguinte, em 1963, A paixão segundo G.H. Diz a própria Autora que passou uns oito anos de aridez, sofreu muito, pensou que não escreveria mais. Mas a partir daquele livro, nas décadas de 60 e 70, a produção é intensa. Sua obra consegue maior divulgação, surgem críticos eminentes, traduções, premiações, teses.

Ela muda de apartamento, no mesmo bairro do Leme, perto de gente famosa. Está preocupada com a educação dos dois filhos e com a saúde do mais velho, Pedro, que mostra indícios de esquizofrenia. 
Na madrugada de 14 de novembro de 1967, há um incêndio em seu apartamento. Fica gravemente ferida, sobretudo na mão direita, a que usava para escrever. Ficou dois meses internada, a mão direita deformada, depois de muitos enxertos, com material tirado das pernas.

Sua beleza tinha sido afetada. Entrou em depressão. Seu filho Paulo diz que ela se fechou muito. Mesmo assim, no fim da vida, consultava-se com Tônia Carrero sobre moda, dicas de maquiagem e coisas desse tipo.

Diz ainda Nádia Gotlib que Clarice não esconde certa estima carinhosa por si mesma. Tal como esse acidente, outros fatos de sua vida são considerados fatais.

Sinto-me tão desamparada, preciso tanto de proteção, porque parece que sou portadora de uma coisa muito pesada. Sei lá porque escrevo! Que fatalidade é esta? Aliás, certa vez leram minha mão e eu perguntei: 'Que sinal é este?' E me disseram: 'Fatalidade'. Realmente algo de grave aconteceu comigo: quase morri em consequência de uma queimadura, passei três dias entre vida e morte, sem garantia. E já iam me cortar a mão, com medo de gangrena. Aí uma irmã minha pediu que esperassem mais um dia. E esse dia me salvou a mão. De repente a vitalidade voltou e refez o estrago. Do mesmo modo - a longo prazo - escrever para mim é uma fatalidade. (GOTLIB, 1995, p. 365-368),

Apraz-me terminar este artigo com as palavras de Hélène Cixous, escritora francesa, grande admiradora de Clarice e que muito escreveu sobre ela:

Ler mulher? Escutem: Clarice Lispector. Primeiramente, Clarice chega assim; tomando-nos de assalto, aparecendo à nossa frente, flecha, veloz voando, pantera que pousa. A cor de seu nome em movimento é evidentemente lispectaranja: uma levemente laranja purpurada pele de mandarina. Mas se tomamos seu nome com mãos delicadas e o desdobramos e o descascamos, seguindo atentamente as indicações dos gomos, segundo sua natureza íntima, vemos aí dezenas de pequenos cristais florescentes, que juntos se refletem em todas as línguas por onde passam as mulheres: Claricelispector. Clar. Ricelis. Celis. Lisp. Clasp. Clarisp. Clarilisp. - Clar - Spec - Tor- Lis - Icelis - Isp - Larice - Ricepector - clarispector - claror - listor - rir - clarir - respeito - respeito - clarespeito - Ice - Claraqui - ó Clarice tu és tu-mesma as vozes da luz, a íris, o olhar, o clarão, a cinticlara laranja diante de nossa janela (CIXOUS, 1999, p. 111). 
Podemos acrescentar, indefinidamente: Clarice, hora da estrela, estrela de mil pontas, horizonte infinito da palavra, sem fronteiras, vislumbrada aurora de um novo texto, que pudesse contornar a rede da vida e da morte.

\section{SINGING THE BLUES}

\section{ABSTRACT:}

This text mainly focus on a Comemorative publisling of releases about 40 years from The bour of the star and the death of its author, Cllarice Lispector.

KEYWORDS: A hora da estrela; Clarice Lispector; Woman; Poverty.

\section{REFERÊNCIAS}

BILENKY, Marlene. Macabéa e seu criador no mundo das Maravilhas. Polímica, São Paulo: Editora Cortez e Moraes, n. 91, p. 152-157, nov./1979.

BORELLI, Olga. Clarice Lispector: esboço para um possível retrato. Rio de Janeiro: Nova Fronteira, 1981.

CIXOUS, Hélène. Viver a Laranja. In: - A bora de Clarice Lispector. Trad. Rachel Gutiérrez. Edição Bilingue. Rio de Janeiro: Exodus, 1999. p. 5-112.

. Extrema fidelidade. In: LISPECTOR, Clarice. A hora da estrela: edição com manuscritos e ensaios. Concepção visual e projeto gráfico Isabel Barreto. 1. ed. Rio de Janeiro: Rocco, 2017. p. 131-163.

GOTLIB, Nádia Batella. Clarice, uma vida que se conta. 3. ed. São Paulo: Ática, 1995.

LISPECTOR, Clarice. A hora da estrela. 1. ed . José Olympio Editora, 1977.

LISPECTOR, Clarice. A hora da estrela: edição com manuscritos e ensaios. Concepção visual e projeto gráfico Isabel Barreto. 1. ed. Rio de Janeiro: Rocco, 2017. . Perto do coração selvagem. 14. ed. Rio de Janeiro: Francisco Alves, 1990.

MOSER, Benjamin. Clarice, uma biografia. Tradução de José Geraldo Couto. São Paulo: Cosac Naify, 2009.

SÁ, Olga de. A escritura de Clarice Lispector. 2. ed. Petrópolis: Vozes; Lorena: Faculdades Integradas Teresa D’Ávila, 1979. 
Clarice, a travessia do oposto. São Paulo: Annablume, 1993.

SPERBER, Suzi Frankl. Jovem com ferrugem. In: SCHWARZ, Roberto (Org.). Os pobres na literatura brasileira. São Paulo: Brasiliense, 1983. p. 154-164.

Recebido em: 24/10/2017. Aprovado em: 02/10/2017. 